\title{
Characterization of the Doxorubicin-Pluronic F68 Conjugate Micelles and Their Effect on Doxorubicin Resistant Human Erythroleukemic Cancer Cells
}

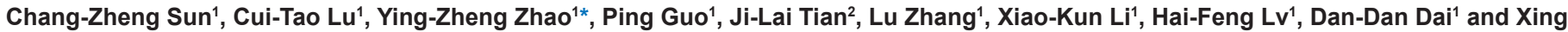
$\mathbf{L i}^{1}$

${ }^{1}$ Wenzhou Medical College, Zhejiang Province 325035, China

${ }^{2}$ Pharmacy Experimental Center, China Pharmaceutical University, Nanjing City, 210009, China

\begin{abstract}
Doxorubicin-pluronic F68 conjugate (DOX-P) was synthesized and its structure was confirmed by FTIR and ${ }^{1} \mathrm{H}-\mathrm{NMR}$ spectra. Using human erythroleukemic cancer cells as model, DOX-P application in chemotherapy was further investigated. Differential scanning calorimetry analysis was applied to compare the fusion and crystallization characterization between pluronic F68 and DOX-P. Morphology and size assessment were measured using a transmission electron microscopy (TEM) to confirm the capability of forming micelles of DOX-P. Tumor cell lines K562 and K562/AO2 were used to investigate the effect of DOX-P on tumor cell resistance. The Tm and Tc of DOX-P were lower than pluronic F68 resulted from the connection of DOX to pluronic F68. Morphology images confirmed the existence of DOX-P micelles, with an average size of about $20 \mathrm{~nm}$. Drug release profile showed that the DOX-P conjugate maintained a sustained DOX release. From cell experiment in vitro, DOX-P micelles could circumvent the DOX resistance of K562/AO2 cells. With advantages of EPR effect and reducing tumor resistance, DOX-P micelles might develop as new tumor targeted delivery system for chemotherapy.
\end{abstract}

Keywords: Polymer-drug conjugate; Micelles; Targeted carrier; Doxorubicin; Drug resistance

\section{Introduction}

Polymer-based drug delivery systems emerged from the laboratory bench in the 1990s as a promising therapeutic strategy for the treatment of cancer and other devastating diseases [1-3]. Polymer-drug conjugates are nano-sized hybrid constructs that covalently combine a bioactive agent with a polymer to ensure not only its efficient delivery to the required intracellular compartment but also its availability within a specific period of time. It has already been demonstrated that polymer-drug conjugation promotes tumor targeting by the enhanced permeability and retention effect and its capability of escaping from reticuloendothelial system.

One promising example of such polymer nanomaterials is presented by a class of Pluronic block copolymers (also known under non-proprietary name poloxamers) [2,4-6]. These block copolymers consist of hydrophilic poly(ethylene oxide) (PEO) and hydrophobic poly(propylene oxide) (PPO) blocks arranged in A-B-A tri-block structure: PEO-PPO-PEO (Figure 1). Due to their amphiphilic character these copolymers display surfactant properties including ability to interact with hydrophobic surfaces and biological membranes. These copolymers self-assemble into micelles in aqueous solutions at concentrations above critical micelle concentration (CMC). The diameters of Pluronic micelles usually vary from $10 \mathrm{~nm}$ to $100 \mathrm{~nm}$.

Doxorubicin (DOX), a topoisomerase inhibitor, is a widely used anticancer drug in the treatment of many types of cancer. However, systemic administration of DOX itself elicits severe cardiac toxicity due

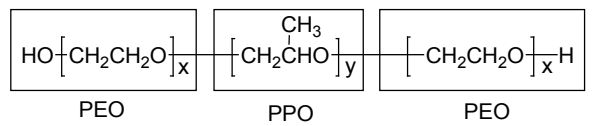

Figure 1: A-B-A tri-block structure of Pluronic block copolymers. to the lack of ability to target cancer cells, and also shows the multidrug resistance (MDR) effect [7-9].

Incorporation of low molecular mass drugs into Pluronic micelles can increase drug solubility and drug stability, and can improve drug pharmacokinetics and biodistribution. Polymeric micelles were utilized for tumor-specific delivery of antineoplastic agents [10,11]. Although DOX is easily sequestered and released from Pluronic micelles in vitro, this type of micelle is not sufficiently stable to be used in vivo. Dilution in the blood upon injection would quickly dissolve the micelle and prematurely release the drug into the blood stream, which limits their practical uses for systemic delivery of DOX. To enhance stability of micelles in the blood stream upon dilution, Pluronic L121 micelles were cross-linked through their hydrophilic shells [12]. To form the crosslinks, the end hydroxyl groups of Pluronic L121 were first chemically converted to aldehydes and then bridged via Schiff bases. This greatly reduced the CMC of the micelles and enhanced the micelle stability.

Recent developments indicate that Pluronic block copolymers can implement more than only inert carrier functions by being biological response modifiers [2,13-15]. Pluronics cause drastic sensitization of MDR tumors to various anticancer agents, enhance drug transport across the blood brain and intestinal barriers, and causes transcriptional

*Corresponding author: Ying-Zheng Zhao, Present address: Pharmacy School, Wenzhou Medical College, Zhejiang Province 325035, China, Tel: 86-57786699363; E-mail: Ictuua@yahoo.com.cn

Received August 24, 2011; Accepted September 30, 2011; Published Octobe 03, 2011

Citation: Sun CZ, Lu CT, Zhao YZ, Guo P, Tian JL, et al. (2011) Characterization of the Doxorubicin-Pluronic F68 Conjugate Micelles and Their Effect on Doxorubicin Resistant Human Erythroleukemic Cancer Cells. J Nanomedic Nanotechnol 2:114. doi:10.4172/2157-7439.1000114

Copyright: ( 2011 Sun CZ, et al. This is an open-access article distributed unde the terms of the Creative Commons Attribution License, which permits unrestricted use, distribution, and reproduction in any medium, provided the original author and source are credited. 
Citation: Sun CZ, Lu CT, Zhao YZ, Guo P, Tian JL, et al. (2011) Characterization of the Doxorubicin-Pluronic F68 Conjugate Micelles and Their Effect on Doxorubicin Resistant Human Erythroleukemic Cancer Cells. J Nanomedic Nanotechnol 2:114. doi:10.4172/2157-7439.1000114

Page 2 of 6

activation of gene expression both in vitro and in vivo. Pluronics have a broad spectrum of biological response modifying activities which make it one of the most potent drug targeting systems available, resulting in a remarkable impact on the emergent field of nanomedicine.

In this study, a pluronic copolymer having multiple carboxyl groups on the PEO terminal was synthesized and then chemically conjugated with DOX via an amide. The synthesized carboxyl-terminated pluronic F68 (CT-Pluronic F68) and doxorubicin-pluronic F68 (DOX-P) were characterized using ${ }^{1} \mathrm{H}-\mathrm{NMR}$, FITR, DSC and transmission electron microscopy (TEM). Morphology and size assessment were measured to confirm the existence of DOX-P micelles. Using K562 and K562/ $\mathrm{AO} 2$ cell lines, in vitro cytotoxicity and cellular uptake behavior were evaluated to observe the effect of DOX-P micelles on DOX resistant human erythroleukemic cancer cells.

\section{Materials and Methods}

\section{Materials}

DOX (API, purity $\geq 98.6 \%$, Lot 090902) was a gift from Hisun Co (TaiZhou, Zhejiang, China). Pluronic F68 (Lot WPIC-630C, $\mathrm{Mw}=8350$ ) was purchased from BASF (ShangHai, China). It has $\mathrm{PEO} / \mathrm{PPO} / \mathrm{PEO}$ monomer unit ratio of 70/35/70. Succinic anhydride (SA), 4-dimethylaminopyridine (DMAP), triethylamine (TEA), N,Ndimethylformamide (DMF), 1-ethyl-3-(3-dimethylaminopropyl)carbodiimide (EDC), N-hydroxysuccinimide (NHS) and DMSO were all analytical reagent purchased from Aldrich Chemical Company. All other chemicals were of analytical grade and used without further purification.

\section{Synthesis of carboxyl-terminated pluronic F68 (CT-Pluronic F68)}

A carboxylic acid group was introduced to the chain end of PEOPPO-PEO (pluronic $\mathrm{F} 68, \mathrm{Mw}=8350$ ) by reaction of the terminal hydroxyl group of pluronic F68 with succinic anhydride as described in the previous study [16]. Briefly, pluronic F68 (18g, 2mmol), succinic anhydride $(0.56 \mathrm{~g}, 3 \mathrm{mmol})$, DMAP $(0.5 \mathrm{~g})$, and TEA $(0.5 \mathrm{ml})$ were dissolved in $30 \mathrm{~mL}$ anhydrous 1,4-dioxane and stirred overnight at 0 , $10,30,50$ and $100^{\circ} \mathrm{C}$ respectively. Then the 1,4-dioxane was removed under a vacuum. The residue was dissolved in chloroform, precipitated into an excess of diethyl ether, and then filtered to remove un-reacted succinic anhydride, DMAP and TEA. With repeating the process twice, the precipitate, carboxyl-terminated pluronic (CT-Pluronic F68, about $79 \%$ yields), was obtained after filtering and drying in a vacuum for $72 \mathrm{~h}$.

\section{Reaction of CT-Pluronic 68 with DOX}

The procedure of the reaction between CT-Pluronic F68 and DOX was as follows: $40 \mathrm{~g}$ (7.4mmol of $-\mathrm{COOH}$ groups) of CT-Pluronic F68 was dissolved in $20 \mathrm{~mL}$ of $\mathrm{N}, \mathrm{N}$-dimethylformamide (DMF) at room temperature. $1 \mathrm{~g}$ of EDC and $2 \mathrm{~g}$ of NHS was added in CT-Pluronic F68 solution. After $15 \mathrm{~min}$ reaction, $2.8 \mathrm{ml}$ of 2 -mercaptoethanol was added to quench the EDC followed by an addition of $3.48 \mathrm{~g}$ of DOX $(6 \mathrm{mmol})$ to the activated CT-Pluronic F68. The activated CT-Pluronic F68 in DMF was reacted with DOX in the presence of triethylamine $(10 \mathrm{mg})$ and stirred at room temperature for $12 \mathrm{~h}$ under nitrogen. The resultant was dialysed against DMF by using a dialysis bag $(\mathrm{MWCO}=3.5 \mathrm{kD})$ for 24 hours and finally lyophilized to gain the product. The DOX content was determined to be $8.5 \mathrm{wt} \%$ by measuring the UV absorbance of a DMSO solution at $480 \mathrm{~nm}$. A calibration curve was constructed using different concentrations of free DOX in DMSO. The conjugation process was monitored by silicon thin-layer chromatography (TLC) method with chloroform: methanol: water (13: 7: $0.5, \mathrm{~V} / \mathrm{V} / \mathrm{V})$ as expanded material.

\section{Confirm of the structure DOX-P}

\section{${ }^{1} \mathrm{H}-\mathrm{NMR}$ and UV-VIS spectra}

The structure of CT-Pluronic F68 and DOX-P copolymer was characterized using 1H-NMR spectroscopy (AVANCE III $600 \mathrm{MHz}$ Bruker, Switzerland) and FT-IR (670 FT-IR, Nicolet, USA). DOX content was measured by UV-VIS spectra (UV-7502 PC, XinMao, ShangHai, China).

\section{Differential scanning calorimetry (DSC)}

The thermal transition of DOX-P was measured with a TA Instruments DSC Q100 (TA Instruments, New Castle, DE) calorimeter and compared with that of Pluronic F68. The samples (10-15 mg) were heated from 0 to $100^{\circ} \mathrm{C}$ under nitrogen atmosphere at a heating rate of $10^{\circ} \mathrm{C} \mathrm{m^{-1 }}$. After $10 \mathrm{~min}$ at $100^{\circ} \mathrm{C}$, the polypropylene samples were crystallized by cooling at a rate of $50^{\circ} \mathrm{C} \mathrm{min}^{-1}$ to $-50^{\circ} \mathrm{C}$ and then reheated to $100^{\circ} \mathrm{C}$.

\section{TEM of DOX-P micelles}

DOX-P $(100 \mathrm{mg})$ in DMSO $(10 \mathrm{ml})$ was added to PBS buffer $(100 \mathrm{ml}$, $\mathrm{P}^{\mathrm{H}}$ 7.4). The appearance of DOX-P solution presented as a transparent reddish solution. To confirm the formation of micelles, morphology and size assessment was measured using a Transmission electron microscopy (TEM, Hitachi, H-7500, Japan). For comparison, Pluronic F68 micelles were used as controls. TEM images were acquired at an operating voltage of $70.0 \mathrm{kV}$. Specimens were prepared by dropping a solution of DOX-P micelles on a cupper grid, followed by air drying for $1 \mathrm{~min}$ and negative staining with phosphotungstic acid (1 wt\%).

\section{Drug release experiment}

Twenty $\mathrm{mg}$ of freeze-dried DOX-P micelles in physiological saline $(20 \mathrm{ml})$ were sealed in a dialysis bag (Mwcutoff: $3.5 \mathrm{kD}$, Spectra /por ), and dialyzed against $30 \mathrm{ml}$ physiological saline with three kinds of $\mathrm{P}^{\mathrm{H}}\left(\mathrm{P}^{\mathrm{H}} 6.0,7.4\right.$ and 8.5$)$ at $37^{\circ} \mathrm{C}$. The outer buffer solution containing released DOX was collected at predetermined time points and replaced with $10 \mathrm{~mL}$ of fresh buffer solutions in order to maintain sink condition. The amount of the released DOX was measured using UV-Vis spectroscopy (UV-7502 PC, XinMao, ShangHai, China) at a $480 \mathrm{~nm}$ wavelength and calculated on the basis of a calibration curve using different concentrations of free DOX in PBS. The experiment was carried out in triplicate.

\section{Cellular uptake study}

DOX resistant human erythroleukemic cancer cells K562/AO2 was maintained in a culture medium containing $1 \mu \mathrm{g} / \mathrm{ml}$ DOX to retain its MDR characteristics. All experiments were performed using cells which had been reselected one to six weeks earlier. K562/AO2 variant were grown in suspension in RPMI 1640 medium. Cell lines were supplemented with $10 \%(\mathrm{v} / \mathrm{v})$ heat-inactivated fetal calf serum and $1 \%$ penicillin/streptomycin at $37^{\circ} \mathrm{C}$ in a humidified atmosphere containing $5 \% \mathrm{CO}_{2}$. All cell culture reagents were obtained from Gibco Life Technologies, Inc. (Grand Island, NY, USA).

For the cellular uptake study, K562 and K562/AO2 were seeded $2 \times 10^{5}$ cells/well in a white 24 -well plate (Corning Costar) with clear bottom in $500 \mu \mathrm{L}$ growth medium containing $5 \mu \mathrm{g} / \mathrm{ml}$ of DOX. Cell culture plates were incubated for different time intervals of 30,60 and $120 \mathrm{~min}$ at $37^{\circ} \mathrm{C}$. Cell suspensions containing DOX were centrifuged 
Citation: Sun CZ, Lu CT, Zhao YZ, Guo P, Tian JL, et al. (2011) Characterization of the Doxorubicin-Pluronic F68 Conjugate Micelles and Their Effect on Doxorubicin Resistant Human Erythroleukemic Cancer Cells. J Nanomedic Nanotechnol 2:114. doi:10.4172/2157-7439.1000114

Page 3 of 6

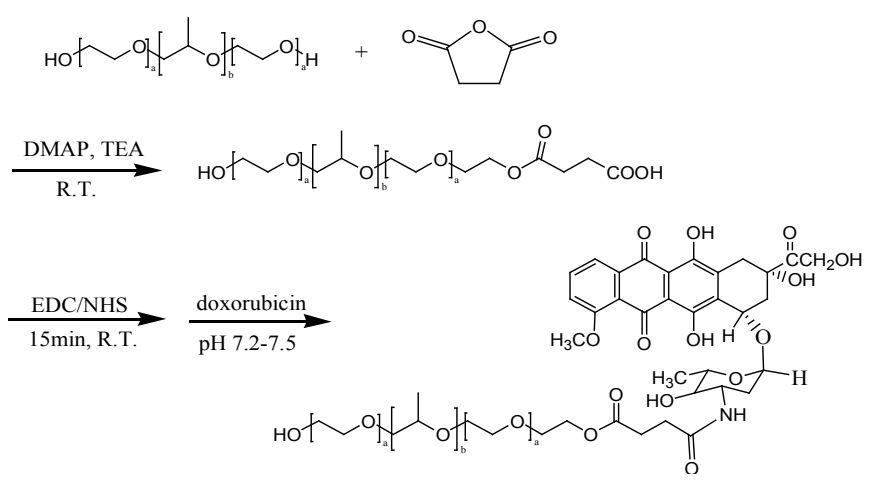

Figure 2: Synthetic route of DOX-P conjugate.

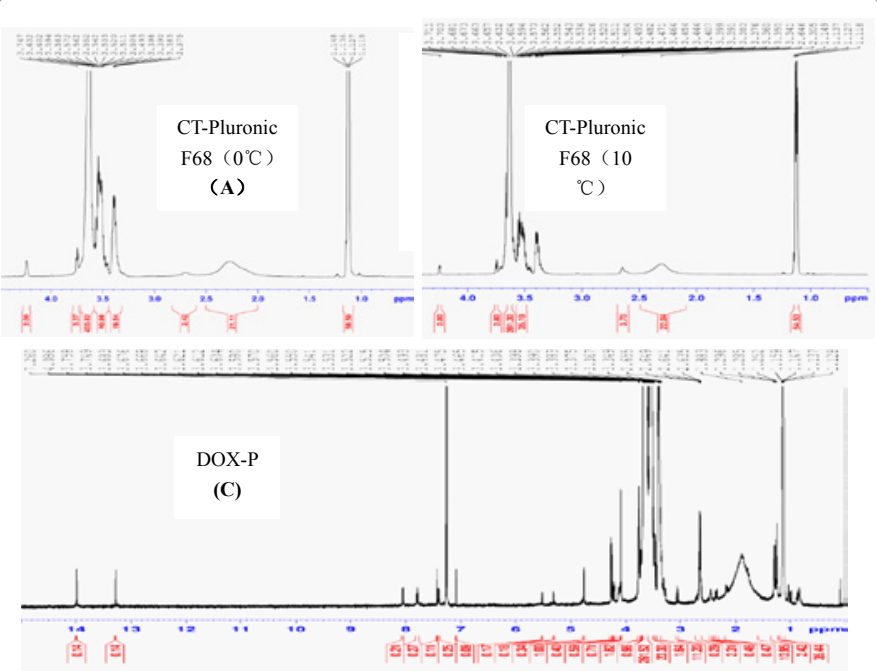

Figure 3: ${ }^{1} \mathrm{H}-\mathrm{NMR}$ spectra of CT-Pluronic $\mathrm{F} 68$ with $0^{\circ} \mathrm{C}$ of reaction $(\mathrm{A}), \mathrm{CT}$ Pluronic $\mathrm{F} 68$ with $10^{\circ} \mathrm{C}$ of reaction (B) and $\mathrm{DOX}-\mathrm{P}(\mathrm{C})$ in $\mathrm{CDCl}_{3}$.

(1500g, 5min) using a centrifuge (Avant ${ }^{\circledR} \mathrm{J}-26$ XP Centrifuge, Beckman Coulter), then the supernatant was removed and the cells were washed three times using ice-cold PBS. Finally all cells were resuspended in $500 \mu \mathrm{l}$ of PBS per well. The relative fluorescence intensity of DOX in 24-well plate was measured at excitation and emission wavelengths of $479 \mathrm{~nm}$ and $587 \mathrm{~nm}$ using fluorescence microplate reader (Spectramax M2, MD, USA).

\section{Cell cytotoxicity of DOX-P in vitro}

For in vitro study, two different tumor cell lines K562 and K562/ $\mathrm{AO} 2$ were used. The in vitro cytotoxicity of DOX and DOX-P were determined by standard MTT assays [17]. Cells were seeded in a 96-well bottom plate at a density of 3000 cells per well and incubated at $37^{\circ} \mathrm{C}$ in a humidified atmosphere with $5 \% \mathrm{CO} 2$ for $24 \mathrm{~h}$. The medium was then replaced with $200 \mu \mathrm{L}$ of medium containing either DOX-P or free DOX (DOX equivalent to $1 \mu \mathrm{g} / \mathrm{mL}$ and $10 \mu \mathrm{g} / \mathrm{mL}$ for $\mathrm{K} 562$ and $\mathrm{K} 562 /$ $\mathrm{AO} 2$ cell lines, respectively). Wells of control groups were treated with equivalent volume of drug free media. The cells were incubated at $37^{\circ} \mathrm{C}$ for $72 \mathrm{~h}$. After incubation, 96-well bottom plate were centrifuged ( 1500 g, 5 min) using a centrifuge (Avant ${ }^{\mathbb{B}}$ J-26 XP Centrifuge, Beckman Coulter). The supernatants were removed, and then MTT $(0.5 \mathrm{mg} /$ $\mathrm{ml}$ ) solutions were added to each well and the plate was incubated for $4 \mathrm{~h}$, allowing the viable cells to reduce the yellow MTT into dark- blue formazan crystals, which were dissolved in $200 \mathrm{~mL}$ of dimethyl sulphoxide (DMSO). The absorbance of individual wells was measured at $560 \mathrm{~nm}$ by a microplate reader (Spectramax M2, MD, USA). All the results obtained from both cytotoxicity assays were confirmed by repeating the experiment on three independent occasions and testing in triplicate each time.

\section{Statistical analysis}

All the experiments were repeated at least three times. Data were expressed as means \pm standard deviation (SD). All results were analyzed by 2 -tailed Student's t-test.

\section{Results and Discussion}

\section{Synthesis and characterization of CT-Pluronic F68 and DOX-P}

The synthesis route of DOX-P was shown in Figure 2. For the synthesis of DOX-P, the end group of pluronic F68 was modified to a carboxyl group. The chemical structure of the carboxyl-terminated pluronic F68 and DOX-P was characterized by FTIR (data was not shown) and ${ }^{1} \mathrm{H}-\mathrm{NMR}$.

The structures of CT-Pluronic F68 and DOX-P were confirmed by ${ }^{1} \mathrm{H}-\mathrm{NMR}$, with taking their spectra in $\mathrm{CDCl}_{3}$. Figure 3 showed the ${ }^{1} \mathrm{H}$-NMR spectra of CT-Pluronic $\mathrm{F} 68$ with $0^{\circ} \mathrm{C}$ of reaction (A), CTPluronic F68 with $10^{\circ} \mathrm{C}$ of reaction (B) and DOX conjugated pluronic F68 (DOX-P). In the spectra of the sharp peak of CT-Pluronic F68 at $2.7 \mathrm{ppm}$ was due to the $-\mathrm{CO}-\mathrm{CH}_{2}-\mathrm{CH}_{2}-\mathrm{CO}$ - protons from the succinic anhydride group, and the peak at $4.3-4.4 \mathrm{ppm}$ was attributed to the $-\mathrm{CH}_{2}-\mathrm{O}$ - protons from the ethylene oxide group adjacent to the succinic anhydride group. These peaks were absent in the ${ }^{1} \mathrm{H}-\mathrm{NMR}$ spectra of DOX conjugated pluronic F68, and a series of new peaks appeared due to the introduction of DOX moieties into the copolymers. Characteristic peaks of DOX (multiple peaks at 4.6-5.5ppm, 7.1-7.8ppm, 13.3-14ppm and $0.8-1 \mathrm{ppm}$ ) were detected. The peak at $8.0-8.1 \mathrm{ppm}$ was attributed to the -CO-NH- group between DOX and CT-Pluronic. Meanwhile, the integral area ratio between - $\mathrm{CO}-\mathrm{NH}$ - and benzene ring was about $1: 3$, which also indicated that the free DOX was removed thoroughly. However, it should be mentioned that the sample consisted of pluronic F68 and CT-Pluronic F68 and about 75mol \% DOX-P.

The degree of substitution was determined with proton nuclear magnetic resonance ( $\left.{ }^{1} \mathrm{H}-\mathrm{NMR}\right)$. The effect of reaction temperature on the degree of substitution was summarized in Table 1. The degree of the esterification of pluronic F68 was calculated from the content of $-\mathrm{CO}-\mathrm{CH}_{2}-\mathrm{CH}_{2}-\mathrm{CO}$ - from succinic anhydride (SA) and -O- $\mathrm{CH}_{2}-\mathrm{CO}-$ between pluronic F68 and SA determined by the ${ }^{1} \mathrm{HNMR}$. As shown in Table 1, the degree of substitution raised with the increase of the ratio of $-\mathrm{CO}-\mathrm{CH}_{2}-\mathrm{CH}_{2}-\mathrm{CO}$ - from $\mathrm{SA}$ and $-\mathrm{O}-\mathrm{CH}_{2}-\mathrm{CO}$ - between pluronic F68 and SA. The molar ratio of $-\mathrm{COOH}$ to PEO-PPO-PEO chains was determined by ${ }^{1} \mathrm{H}-\mathrm{NMR}$ to be about 154.2: 100 (equivalent to a degree of substitution about $78 \mathrm{~mol} \%$ ) while the reaction temperature was $10^{\circ} \mathrm{C}, 30^{\circ} \mathrm{C}$ and $50^{\circ} \mathrm{C}$. When the reaction temperature reduced

\begin{tabular}{|l|l|l|}
\hline Temperature $\left({ }^{\circ} \mathrm{C}\right)^{\mathrm{TM}}$ & Yield (wt. \%) & Degree of substitution (mol. \%) \\
\hline 0 & 89 & 46 \\
\hline 10 & 89 & 78 \\
\hline 30 & 88 & 79 \\
\hline 50 & 89 & 78 \\
\hline 100 & 85 & - \\
\hline
\end{tabular}

Table 1: Effect of reaction temperature on the degree of substitution for the esterification of pluronic F68 with succinic anhydride 
Citation: Sun CZ, Lu CT, Zhao YZ, Guo P, Tian JL, et al. (2011) Characterization of the Doxorubicin-Pluronic F68 Conjugate Micelles and Their Effect on Doxorubicin Resistant Human Erythroleukemic Cancer Cells. J Nanomedic Nanotechnol 2:114. doi:10.4172/2157-7439.1000114

Page 4 of 6
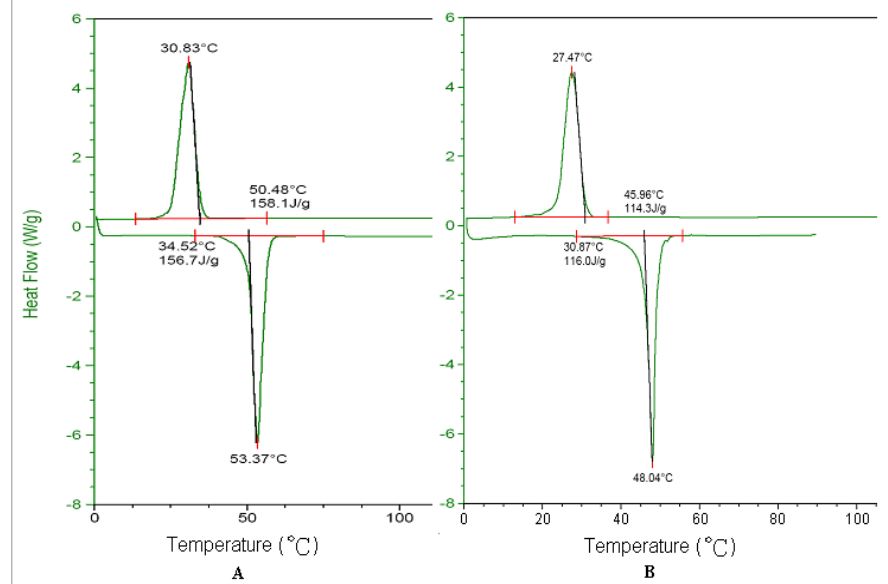

Figure 4: DSC thermograms of Pluronic F68 (A) and DOX-P (B).
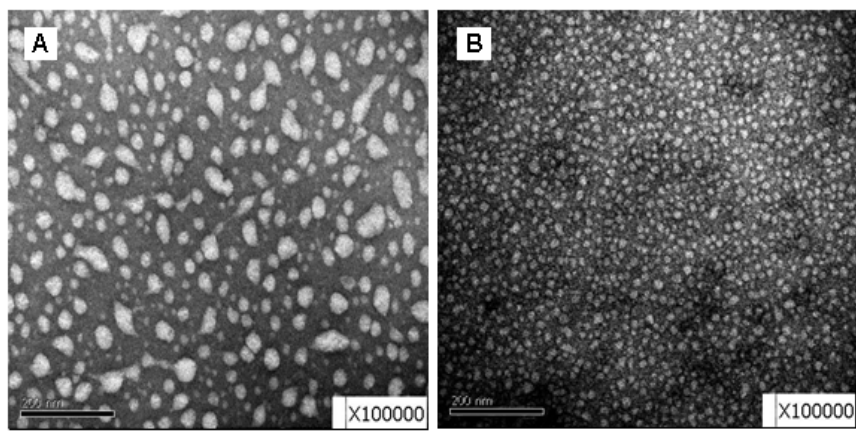

Figure 5: TEM images of Pluronic 68 micelles $(A)$ and DOX conjugated micelles (B). The scale bars indicate $200 \mathrm{~nm}$

to $0^{\circ} \mathrm{C}$, the degree of substitution was decreased to $46 \mathrm{~mol} \%$. Higher temperatures (such as $100^{\circ} \mathrm{C}$ ) might lead to a degradation of the PEOPPO-PEO chains which were not thermodynamically stable. In this study, CT-Pluronic F68 obtained at $10^{\circ} \mathrm{C}$ was used to react with DOX. The DOX content in DOX-P was determined to be 8.5 wt. \% by UV measure at $480 \mathrm{~nm}$, which confirmed the successful synthesis of the DOX-P.

Differential scanning calorimetry can be used to measure a number of characteristic properties of nanoparticles. With this technique, it is possible to observe fusion and crystallization characteristics of polymers. As the temperature increases the sample eventually reaches its melting temperature $\left(T_{m}\right)$. The melting process results in an endothermic peak in the DSC curve. The transition at crystallization temperature $(T)$. From amorphous solid to crystalline solid is an exothermic process, and results in a peak in the DSC signal. As shown in Figure 4, the Tm and Tc of DOX-Pluronic F68 comparing with pluronic F68 were both declined from $53.37^{\circ} \mathrm{C}$ to $48.04^{\circ} \mathrm{C}$ and $30.83^{\circ} \mathrm{C}$ to $24.47^{\circ} \mathrm{C}$. The decrease of $\mathrm{Tm}$ and $T_{c}$ might be resulted from the connection of DOX to pluronic F68.

\section{TEM of DOX-P micelles}

To investigate the DOX-P's capability of forming micelles, TEM images of DOX-P micelles or pluronic F68 micelles were taken. Figure 5 showed the morphology of pluronic 68 micelles and DOX conjugated micelles. As shown in Figure 5A, pluronic F68 micelles were irregular in shape and showed an average size of about $50 \mathrm{~nm}$. However, DOX-P micelles showed tightly packed nanospheres with an average size of about $20 \mathrm{~nm}$ (Figure 5B). It was likely that hydrophobic interaction stacking of conjugated DOX molecules in the core were responsible for the self-assembling core/shell structure of DOX-P micelles, which would make the micelles more stable in theory [12]. It is known that drug encapsulation in micelles can diminish drug extravasation into normal tissues and provide for a passive drug targeting to tumors via the enhanced permeability and retention (EPR) effect. The EPR effect is realized due to abnormally high permeability of tumor blood vessels combined with prolonged circulation of the micelles due to their decreased extravasations in normal vessels and lack of renal clearance $[1,10,13,14]$. From TEM results, DOX-P micelles might be used as a promising system for cancer therapy.

\section{Drug release experiment}

From the literature reports, the side chain hydrolysis of polymers depends on the strength and chemical nature of the polymer-drug bonds, the structure of polymer and medium conditions. As shown in Figure 6, hydrolysis behaviour of DOX-P micelles in vitro was studied in buffer solutions with different $\mathrm{P}^{\mathrm{H}} \mathrm{s}\left(\mathrm{P}^{\mathrm{H}} 6.0,7.4\right.$ and 8.5$)$ at $37^{\circ} \mathrm{C}$. Under different $\mathrm{P}^{\mathrm{H}}$ conditions, DOX release profiles showed similar increasing trend with time. In 14 day, up to $70-100 \%$ of the loaded DOX could be released from DOX-P conjugate, which was attributed to the gradual hydrolysis of the amide and ester bond between DOX and the side chain of the polymer. The difference of DOX release with $\mathrm{P}^{\mathrm{H}}$ was remarkable. The release of DOX from the micelles was accelerated when the $\mathrm{P}^{\mathrm{H}}$ was reduced to 6.0 or increased to 8.5 comparing with $\mathrm{P}^{\mathrm{H}}$ 7.4's condition. The sustained release of DOX from DOX-P was similarly observed in formulations of microspheres and nanoparticles that were prepared by the conjugation of various hydrophilic drugs to polymers $[18,19]$

\section{Cellular uptake study}

The efficacy of chemotherapy treatment in many types of cancers is severely limited by MDR. Cancers with the MDR phenotype overexpress efflux transporters belonging to a superfamily of ATP binding cassette proteins, such as P-gp and MDR associated proteins that pump drugs out of cells. It is reported that Pluronic copolymers can inhibit P-gp function $[2,10]$.

The cellular uptake of DOX by K562 and K562/AO2 cell lines at $37^{\circ} \mathrm{C}$ for distinct durations were shown in Figure $7 \mathrm{~A}$ and Figure $7 \mathrm{~B}$,

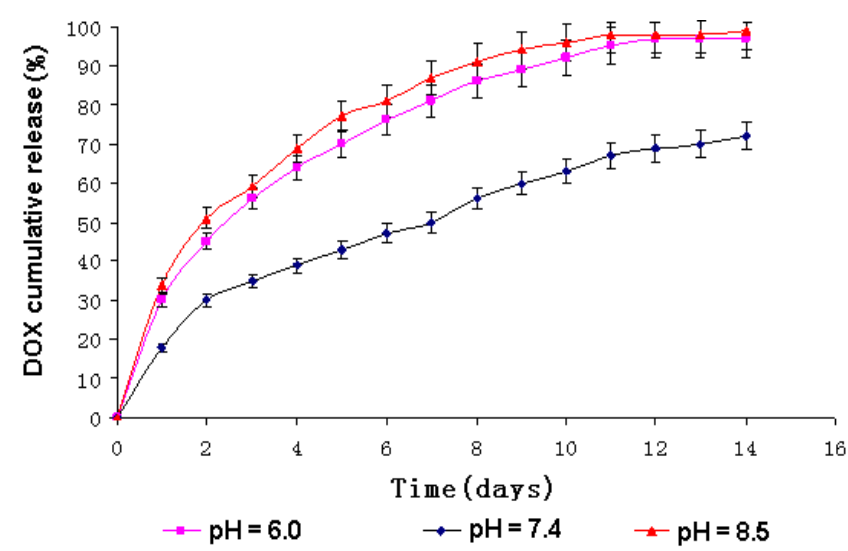

Figure 6: In vitro release profiles of DOX from DOX-P micelles depending on the $\mathrm{pH}$ value of environment: (filled circle) $\mathrm{P}^{\mathrm{H}} 7.4$, (filled square) $\mathrm{P}^{\mathrm{H}} 6.0$ and (filled triangle) $\mathrm{P}^{\mathrm{H}} 8.5, \mathrm{~T}=37^{\circ} \mathrm{C}$. (mean $\pm \mathrm{SD}, \mathrm{n}=3$ ). 
Citation: Sun CZ, Lu CT, Zhao YZ, Guo P, Tian JL, et al. (2011) Characterization of the Doxorubicin-Pluronic F68 Conjugate Micelles and Their Effect on Doxorubicin Resistant Human Erythroleukemic Cancer Cells. J Nanomedic Nanotechnol 2:114. doi:10.4172/2157-7439.1000114

Page 5 of 6
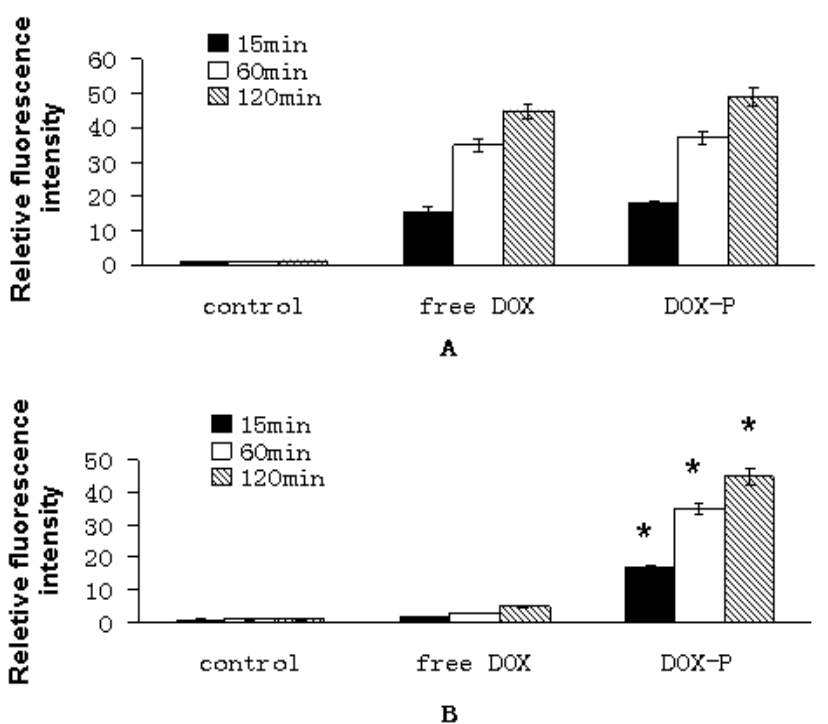

Figure 7: DOX mean fluorescence intensity of the K562 (A) and K562/AO2 (B) cells incubated with $0.9 \mathrm{w} / \mathrm{v} \%$ saline, free DOX, DOX-P (DOX equivalent to $5 \mu \mathrm{g} / \mathrm{ml}$ ) for $15 \mathrm{~min}, 60 \mathrm{~min}$ and $120 \mathrm{~min}($ mean $\pm \mathrm{SD}, \mathrm{n}=6)$ ) * $\mathrm{p}<0.05$ compared with free DOX.

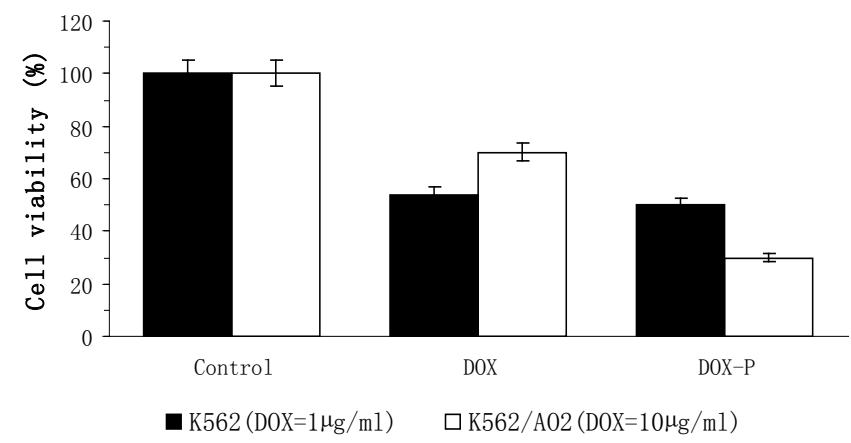

${ }^{*} \mathrm{p}<0.05$ compared with DOX.

Figure 8: Cell viability of $\mathrm{K} 562$ and $\mathrm{K} 562 / \mathrm{AO} 2$ cells with $0.9 \mathrm{w} / \mathrm{v} \%$ saline, DOX DOX-P following incubation for $72 \mathrm{~h}$ at $37^{\circ} \mathrm{C}$ (mean $\left.\pm S D, n=6\right)$.

respectively. As shown in Figure 7A, there was no significant difference in the cellular uptake of DOX from different formulations $(P>0.05)$. Free DOX might transport across the cell membrane through diffusion in $\mathrm{K} 562$ cells, a pathway that was affected in K562/AO2 cells by P-gp [20]. As shown in Figure 5B, after exposure of K562/AO2 cells to DOX solution, the accumulation of DOX in cells was limited throughout the entire course of the study. It suggested that entered DOX could be extruded out of K562/AO2 cells by the P-gp efflux pump. In DOX-P solution, however, the accumulation of DOX in K562/AO2 cells enhanced with increased duration of incubation. It indicated that Pluronic copolymers could effectively inhibit P-gp function $[13,14]$ and therefore help to circumvent the DOX resistance of K562/AO2 cells.

\section{Cell cytotoxicity of DOX-P in vitro}

Figure 8 showed the cytotoxicities of free DOX and DOX-P against K562/AO2 cells. In this experiment, freshly prepared DOX-P solution was used to test the in vitro cytotoxicity. For comparison, the concentration of DOX in DOX-P solution was adjusted to be the same as that of free DOX. From Figure 8, DOX-P solution showed more cytotoxic effect upon K562/AO2 cells than DOX solution $(P<0.05)$. However, there is little difference for the viability of K562 cells from DOX-P solution and DOX solution $(P>0.05)$. This result confirmed the enhancement effect of DOX-P micelles for DOX uptake and DOX resistant inhibition.

\section{Conclusions}

In this paper, CT-Pluronic F68 was used to synthesize a new doxorubicin-pluronic F68 conjugate (DOX-P). Its related characterization and cell cytotoxicity were investigated. The structures of CT-Pluronic F68 and DOX-P were confirmed by FTIR and ${ }^{1} \mathrm{H}-\mathrm{NMR}$ spectra. The $\mathrm{T}_{\mathrm{m}}$ and $\mathrm{T}_{\mathrm{c}}$ of DOX-P were lower than pluronic $\mathrm{F} 68$ resulted from the connection of DOX to pluronic F68. Morphology and size assessment were measured using a transmission electron microscopy (TEM) to confirm the capability of forming micelles of DOX-P. DOX-P micelles showed tightly packed nanospheres with an average size of about $20 \mathrm{~nm}$. Drug release profile showed that the DOX-P conjugate maintained a sustained DOX release. From cell experiment in vitro, DOX-P micelles could circumvent the DOX resistance of K562/AO2 cells. With advantages of EPR effect and reducing tumor resistance, DOX-P micelles might developed as new tumor targeted delivery system for chemotherapy. Further study will focus on the characterization and application DOX-P micelles comparing with DOX physically entrapped pluronic F68 micelles in vitro and in vivo.

\section{Acknowledgements}

This research was supported by the National Natural Science Funds (30870755, 81071277, 81071164), Natural Science Foundation of Zhejiang Province (Y2110587, Y2080915), Natural Science Foundation of Beijing (7112100), Scientific Research Joint Funds of Health Ministry and Zhejiang Province (WKJ2011-2-010), Medicine and Health Grant from Wenzhou Bureau of Science and Technology (S20100049, H20100017, Y20100029), Zhejiang Province funds for Health Department (2010ZQ007, 2011ZDA017), Zhejiang Province funds for Education Department (Y201016664).

\section{Declaration of Interest}

The authors report no conflicts of interest. The authors alone are responsible for the content and writing of this paper.

\section{References}

1. Langer $R$ (1998) Drug delivery and targeting. Nature 392: 5-10.

2. Batrakova EV, Li S, Brynskikh AM, Sharma AK, Li Y, et al. (2010) Effects of pluronic and DOX on drug uptake, cellular metabolism, apoptosis and tumo inhibition in animal models of MDR cancers. J Control Release 143: 290-301.

3. Danquah MK, Zhang XA, Mahato RI (2010) Extravasation of polymeric nanomedicines across tumor vasculature. Adv Drug Deliv Rev 63: 623-639.

4. Kabanov A, Nazarova I, Astafieva I, Batrakova E, Alakhov V, et al. (1995) Micelle formation and solubilization of fluorescent probes in poly(oxyethyleneboxypropilene-b-oxyethylene) solutions. Macromolecules 28: 2303-2314.

5. Oerlemans C, Bult W, Bos M, Storm G, Nijsen JF, et al. Polymeric micelles in anticancer therapy: targeting, imaging and triggered release. Pharm Res 27 : 2569-2589.

6. Croy SR, Kwon GS (2006) Polymeric micelles for drug delivery. Curr Pharm Des 12: 4669-4684.

7. Marchi N, Hallene KL, Kight KM, Cucullo L, Moddel G, et al. (2004) Significance of MDR1 and multiple drug resistance in refractory human epileptic brain. BMC Med 2: 37.

8. Lu CT, Zhao YZ, Wu Y, Tian XQ, Li WF, et al. (2010) Experiment on enhancing antitumor effect of intravenous epirubicin hydrochloride by acoustic cavitation in situ combined with phospholipid-based microbubbles. Cancer Chemother Pharmacol 68: 343-348.

9. Marin A, Sun H, Husseini GA, Pitt WG, Christensen DA, et al. (2002) Drug 
Citation: Sun CZ, Lu CT, Zhao YZ, Guo P, Tian JL, et al. (2011) Characterization of the Doxorubicin-Pluronic F68 Conjugate Micelles and Their Effect on Doxorubicin Resistant Human Erythroleukemic Cancer Cells. J Nanomedic Nanotechnol 2:114. doi:10.4172/2157-7439.1000114

delivery in pluronic micelles: effect of high-frequency ultrasound on drug release from micelles and intracellular uptake. J Control Release 84: 39-47.

10. Kabanov A, Alakhov VY (2002) Pluronic block copolymers in drug delivery: from micellar nanocontainers to biological response modifiers. Crit Rev Ther Drug Carr Syst 19: 1-72.

11. Krupka TM, Weinberg BD, Wu H, Ziats NP, Exner AA (2007) Effect of intratumoral injection of carboplatin combined with pluronic P85 or L61 on experimental colorectal carcinoma in rats. Exp Biol Med (Maywood) 232: 950957.

12. Yang TF, Chen CN, Chen MC, Lai CH, Liang HF, et al. (2007) Shell-crosslinked pluronic L121 micelles as a drug delivery vehicle. Biomaterials 28: 725-734.

13. Kabanov AV, Batrakova EV, Alakhov VY (2002) Pluronic block copolymers for overcoming drug resistance in cancer. Adv Drug Deliv Rev 54: 759-779.

14. Batrakova EV, Kabanov AV (2008) Pluronic block copolymers: Evolution of drug delivery concept from inert nanocarriers to biological response modifiers. J Control Release 130: 98-106.
15. Huang J, Si L, Jiang L, Fan Z, Qiu J, et al. (2008) Effect of pluronic F68 block copolymer on P-glycoprotein transport and CYP3A4 metabolism. Int J Pharm 356: 351-353.

16. Tian JL, Zhao YZ, Jin Z, Lu CT, Tang QQ, et al. (2010) Synthesis and characterization of Poloxamer 188-grafted heparin copolymer. Drug Dev Ind Pharm 36: 832-838.

17. Twentyman PR, Luscombe M (1987) A study of some variables in a tetrazolium dye (MTT) based assay for cell growth and chemo sensitivity. Br J Cancer 56 279-285.

18. Yoo HS, Oh JE, Lee KH, Park TG (1999) Biodegradable nanoparticles containing DOX-plga conjugates cytosis of dox-plga-peg micelles for sustained release. Pharm Res 16: 1114-1118.

19. Yoo HS, Park TG (2000) In vitro and in vivo anti-tumor activities of nanoparticles based on DOX-PLGA conjugates. J Control Release 68: 419-431.

20. Mahmud A, Lavasanifar A (2005) The effect of block copolymer structure on the internalization of polymeric micelles by human breast cancer cells. Colloids Surf B Biointerfaces 45: 82-89. 